without examination? And do not all these bodies exact fees in return for the honour conferred?

There can be no objection to the Fellowship of any learned body being conferred on worthy subjects by the votes of the existing Fellows, but I fully admit that the candidates should first have proved themselves to be deserving of the honour.

March 1st, 1881.

I remain, Sir, yours obediently,

F.R.C.S. EDrN.

** Though the mode of election of Fellows of the R.C.P. London may not be perfectly satisfactory, our correspondent must be aware that the process and the results are very different from those of the Scotch Corporations. A Fellowship cannot be bought at the London College as in Edinburgh, but it is conferred as a mark of distinction by the suffrages of the Fellows of the College. The system of election in the Kring and Queen's College of Ireland is, we fear, too like that of the Scoteh Corporations. But neither in the English nor the Irish College of Surgeons is the Fellowship to be had now without examination, except as regards the latter in certain rare and well-defined cases. The only instances in which the Fellowship of the Royal College of Surgeons of England can be obtained without examination are (1) in the case of persons who were Members before Sept. 14th, 1843, on the recommendation of six Fellows; (2) the Council of the College has the power to elect annually two.Members of twenty years' standing, but there are only three Fellows who have been elected in this way ; (3) by an ad eundem admission of Fellows of the Irish College of Surgeons, of which there are two. It is satisfactory to know that all these questions are to be investigated by a Royal Commission.-ED. L.

\section{THE POTTED MEAT TRADE.}

\section{To the Editor of THE LANCET.}

SIR,-If there is one trade that requires supervision it is the potted meat trade. For several years past I have from time to time had very clear cases of poisoning from the use of potted meats as sold in the country. In one instance a lady had some potted salmon for luncheon; in less than an hour she was taken violently ill with sickness, pain in the region of the stomach, and a feeling of faintness. One of her daughters was similarly, though in a less degree, affected; neither of the ladies had the smallest doubt that the potted salmon was the cause of the illness. Another time several boys were affected with sickness and great gastric disturbance; that was also attributed to potted fish, lobster, if I remember rightly. Again, a pot of so-called potted shrimps that had disagreed with two boys was sent to me. I found that it mainly consisted of a pultaceous substance, coloured with venetian red. Under a low-power microscope fragments of small crab shells were found to be abundant. The mass seemed to be composed of pounded crabs, possibly some herring roe, grease of some kind, and venetian red. In another instance a tin of potted food was brought to me. It looked fresh, and from the cover it seemed to be just out of the manufactory. There was a small tear in the cover, and on enlarging the hole another cover was seen underneath entirely defaced by ironmould, so that it is possible for the potted contents of the tin to have been years old and to have been fraudulently made to look new by placing a clean and new label upon it. It will be in the recollection of many how a large quantity of the tinned meat that was supplied by a respectable firm for use in the Crimea was discovered at Devonport, fortunately before shipment, to be in a putrid and utterly unusable condition. I have been led to inake these statements and remarks from having had the following extract from the Huddersfield Examiner given to me:-

\section{"A Potted Meat Manufuctory: Disgusting Discovery.}

"On Saturday a disgusting discovery was made on the premises of a potted meat manufacturer. Entering the premises Superintendent Buckley and Inspector Latham found in the manufactory a steam machine in operation, and about $1300 \mathrm{lb}$. of diseased horseflesh, mutton, $\& c$, in various stages, from the 'raw material' to the 'finished' potted meat, sausages, saveloys, savoury ducks, German polonies, \&c. There were nearly $200 \mathrm{lb}$ weight of sausages recently made, and coloured wit red ochre to give them a fresh appearance. Two diseased sheep, dressed but uncut, were in the manufactory, besides quarters, breasts, legs, and shoulders of diseased mutton, besides $200 \mathrm{lb}$. weight of diseased horseflesh, cut into small pieces, cans of recently made potted meat, the meat being mostly horseffesh, horribly diseased and coloured with red ochre, large German polonies of equally unwholesome, if not poisonous, material, and a large number of tins ready to receive as potted meat the strange compounds. The borough and county medical officers immediately condemned the meat, remarking that they had never seen such a disgusting collection. A tin of red ochre was also found in the loathsome manufactory. Magisterial proceedings will neeessarily follow."

I understand that the magistrates inflicted three months imprisonment, remarking that it was the utmost penalty that they could enforce. It is impossible to use too strong terms against such nefarious proceedings, and while the alarm of trichina is occupying the public mind the abomi nation to which the potted meat trade can descend ought not to be lost sight of.-Yours very truly,

Marlborough College, March 7th, 1881. WALTER FERGUS, M.D.

\section{CYSTICERCUS IN THE BRATN.}

\section{To the Editor of THE LANCET.}

SIR,-The occurrence of pork measles in the human brain is so rare that perhaps you will allow me to mention that Dr. Flint of Scarborough has just sent me a specimen of Cysticercus cellulosæe which, apart from its unusual habitat and the clinical interest attaching to it, exhibits some strango peculiarities. In the uninjured state the bladder-worm was fully as large as a cherry, having the width of a shilling piece. When unrolled and gently extended on a slide it reached a length of two inches. On dissecting out the heal I was not a little surprised to find that it was furnished with six suckers. This reminds one of Zenker's example of a monstrous Tænia solium recently figured and described by Heller ("Die Schmarotzer,"s. 41). It is to be hoped that Dr. Flint will publish his case. The specimen will be shown at the next meeting of the Quekett Club.

I am, Sir, yours truly,

London, March 7th, 1881. T. SPENCER COBBOLD.

\section{EMPYEMA AND ITS TREATMENT BY FREE INCISION, IRRIGATION, AND ASPIRATION.}

To the Editor of THE LANCET.

SIR,-Mr. Lowe is a little severe upon me in his criticism of my case.

Firstly, he thinks I claim priority in performing the above operation by free incision, irrigation, and aspiration, with. Listerian precautions. I assure him I do not. All that I say in my little paper is, that this case (he one reported) may be the first done according to the directions of Professor Fraentzel, as given in Ziemssen's Cyclopædia; and I may add, by the way, that Fraentzel in this article says he himself derived the plan of proceeding from Traube. This, ny "claim," however, is sufficiently disposed of by a report in the last number of THE LANCET, by Dr. Ferguson of Cheltenham, of two cases, one of which, at any rate, was treated in 1879 , and I am pleased to acknowledge his priority, as also to find he appreciates the operation as he does. As I only followed implicitly Fraentzel's directions, I will leave him to fight out with $\mathrm{Mr}$. Lowe, if he thinks proper, the science and common sense of the arrangements, just adding that if Mr. Lowe would read his beauriful article on Pleurisy, he would not, I am sure, think him deficient in either the one or the other.

The distilled water was only used for the first forty-eing hours, and was heated to from $100^{\circ}$ to $143^{\circ} \mathrm{F}$. I am in hove it washed away all disease germs then existing, and that the subsequent antiseptic washings destroyed any, if intruduced by it. As to the other Listerian precautions, all were carried out-instruments, tubes, hands, funnel, syringe, and even clothes, were freely carbolised. The spray was nsed during all manipulations, and carbolised gauze applied after. 